\title{
SISTEM INFORMASI KEANGGOTAAN PERGERAKAN MAHASISWA ISLAM INDONESIA (PMII) KABUPATEN BANJAR
}

\author{
Fathul Hafidh ${ }^{\text {a,1 }}$, Mirza Yogy Kurniawan ${ }^{\text {b,2 }}$, Rezky Izzatul Yazidah Anwar ${ }^{\mathrm{c}, 3}$ \\ ${ }^{a}$ Fakultas Teknologi Informasi, Universitas Islam Kalimantan Muhammad Arsyad Al Banjari, Banjarmasin \\ ${ }^{b}$ Fakultas Teknologi Informasi, Universitas Islam Kalimantan Muhammad Arsyad Al Banjari, Banjarmasin \\ ${ }^{c}$ Fakultas Teknologi Informasi, Universitas Islam Kalimantan Muhammad Arsyad Al Banjari, Banjarmasin \\ ${ }^{1}$ hafidh@uniska-bjm.ac.id; ${ }^{2}$ mirza.yogy@gmail.com; ${ }^{3}$ rezky.izzatul@uniska-bjm.ac.id \\ * corresponding author
}

ARTICLE INFO

Keywords

Organization, Indonesian

Islamic Student Movement

(PMII), Information System.

\section{ABSTRACT}

The Indonesian Islamic Student Movement (PMII) Banjar Regency is a forum for association of student organizations within the Banjar Regency. The registration process for organizational members is carried out conventionally, which must come to the PMII Kabupaten Banjar then filled out all available forms and collected them back to the administration department. Then a written test is held which will be held on the specified day, after the participant is declared to have passed, then the participant will be invited to carry out an interview test. Documentation of activities on books and paper causes data recording to take a long time due to different handwriting and difficulty in reading them, books and paper are also prone to damage and loss. It is very difficult to find data from previous registered member because there is no good documentation. There is also no standard committee election fee, which creates difficulties in choosing a new committee. With the Information System, the registration service process, written tests until interviews can be well documented and stored, data retrieval becomes faster also data management is more structured. The management system for each member also facilitates the management of existing members in the PMII Kabupaten Banjar and can be used as a reference when forming a committee. Testing User Acceptance on the application of the system gets Cronbach Alpha value of 0.654 , which means that the reliability is included.

\section{Pendahuluan}

Revolusi di bidang sistem informasi dimulai dari penggabungan antara teknologi komputer dengan telekomunikasi. Saat ini dalam hitungan detik data atau informasi dapat dikirimkan kemana saja melalui teknologi komputer dan telekomunikasi. Tidak berlebihan jika salah satu pakar IBM menganalogikan perkembangan teknologi informasi dengan perkembangan otomotif sebagai berikut: "seandainya dunia otomotif mengalami kemajuan sepesat teknologi informasi, saat ini telah dapat diproduksi sebuah mobil berbahan bakar solar, yang dapat dipacu hingga kecepatan maximum 10,000 km/jam, dengan harga beli hanya sekitar 1 dolar Amerika!”. Menjelaskan bahwa bagaimana evolusi perkembangan teknologi informasi saat ini berkembang pesat secara signifikan dan mempengaruhi persaingan antara perusahaan-perusahaan di dunia, khususnya yang bergerak di bidang jasa [1]. Salah satu cara mengoptimalkan kinerja individu dalam suatu organisasi/perusahaan yaitu dengan 
penerapan teknologi sistem informasi baru yang diikuti dengan kepercayaan dari pemakai terhadap sistem informasi baru tersebut [2].

Kemunculan Pergerakan Mahasiswa Islam Indonesia (PMII) dilatarbelakangi untuk menjawab dan sebagai respon dari berbagai macam persoalan kebuntuan-kebuntuan struktural, kultural dan konstitusional lembaga-lembaga politik, sosial, budaya dan hukum yang telah ada [3]. PMII Kabupaten Banjar merupakan wadah perkumpulan organisasi kemahasiswaan dilingkungan Kabupaten Banjar. Anggotanya terdiri dari beberapa Sekolah Tinggi dan Akademi yang ada di Kabupaten Banjar. Tahun ini anggota yang mendaftar kurang lebih 501 orang terdiri atas 397 Lakilaki dan 104 Perempuan.

PMII merupakan organisasi yang berada di luar birokrasi kampus. Organisasi PMII biasanya berperan sebagai kader-kader yang bergerak di seluruh penjuru Indonesia pola komunikasi organisasi dilakukan secara vertikal di PMII Kota Malang berjalan dengan baik namun pelaksanaan komunikasi organisasi tidak hanya dilakukan antara pimpinan organisasi atau secara vertikal saja, komunikasi organisasi secara horizontal juga harus dilakukan sedangkan hambatannya yaitu kurangnya prosedur kerja atau rencana kerja dalam menjalankan fungsi dan tanggung jawab di bidangnya masing-masing yang dapat mempermudah jalannya komunikasi dari tingkatan pengurus cabang hingga pengurus rayon [4].

Kaderisasi formal yang dilakukan PMII ada 3 bentuk yaitu MAPABA (Masa Penerimaan Anggota Baru) PKD (Pelatihan Kader Dasar) dan PKL (Pelatihan Kader Lanjut). Dimana ketiga kaderisasi formal itu dilaksanakan secara berantai, berkelanjutan dan penyempurnaan pencapaian yang ditandai dengan konpetensi diranah kognitif, afekti dan psikomotoriknya sebagai ukuran peningkata kualitas atau kapasitas kader PMII [5].

Rekrutmen anggota PMII di beberapa perguruan tinggi diadakan setiap tahun dan ditangani oleh pengurus rayon atau komisariat [6]. Proses rekrutmen masih dilakukan secara konvensional, yaitu harus datang ke sekretariat PMII Kab. Banjar kemudian mengisi semua formulir yang tersedia dan mengumpulkannya kembali ke bagian administrasi. Kemudian terdapat tes tertulis yang dilaksanakan pada hari yang telah ditetapkan, setelah peserta dinyatakan lulus, kemudian peserta akan diundang untuk melaksanakan tes wawancara untuk mengetahui minat bakat hingga kemampuan peserta dalam berorganisasi [7]. Setelah proses tersebut selesai, peserta akan resmi menjadi anggota PMII. Setelah proses pendaftaran selesai, mereka harus selalu aktif menanyakan kegiatan kaderisasi yang akan berlangsung, karena semua kegiatan hanya diinformasikan melalui mading sekretariat PMII ataupun grup sosial media PMII. Setelah mereka dinyatakan lulus dan menjadi kader, akan mendapatkan almameter dan kartu anggota. Saat ini pada PMII Kabupaten Banjar tidak ada data yang akurat mengenai data anggota aktif, data anggota yang telah purna. Hal ini juga menyulitkan komunikasi dari PMII kepada anggota yang telah purna.

Pengembangan aplikasi Sistem Informasi Keanggotaan telah dilakukan Hulliyana (2016) yang mana dapat dilakukan sesuai dengan analisa dan perancangan yang mana dapat memberikan kemudahan kepada kader untuk mencari informasi anggota tertentu. Selanjutnya aplikasi yang dikembangkan juga dapat memudahkan dalam hal membuat laporan data anggota dan indeks jati diri kader [8]. Serta Islamy (2020) membuat pelaporan kegiatan dan lain sebagainya dilakukan dengan sebuah sistem yang dapat melakukan pengotomatisan seluruh laporan, sehingga penilaian yang didapatkan adalah penilaian yang bersifat objektif [9]. Pada penelitian ini pengelolaan menyeluruh sesuai sistem yang berjalan pada proses kaderisasi, dimulai dari fasilitas pendaftaran, adanya tes tertulis kemudian penginputan nilai wawancara, hingga pengakumulasian nilai keseluruhan dapat menjadi pertimbangan ketika akan menerima anggota baru tersebut. Selain itu kader yang telah terdaftar dapat melakukan penginputan kegiatan, pengalaman, keterampilan dan pendidikan yang setelah terinput admin dapat memberikan bobot penilaian atas data kegiatan, pengalaman, keterampilan ataupun data pendidikan yang telah diinput, sehingga nantinya dapat menjadi pertimbangan dalam penilaian keaktifan ataupun penilaian tingkat keterampilan kader tersebut.

Dengan adanya Sistem Informasi kaderisasi menjadikan sistem ini dapat memberikan layanan pendaftaran, tes tertulis dan penilaian wawancara hingga menjadi anggota dan terdapat pengelolaan 
data berupa data pendidikan, keterampilan, pengalaman dan kegiatan dari anggota. Pada Sistem informasi ini juga memiliki keunggulan dalam penyimpanan data, keakuratan data hingga kemudahan dalam pencarian. Adanya sistem penilian pada tiap inputan anggota juga memudahkan penilaian terhadap anggota-anggota yang ada pada organisasi PMII Kab. Banjar. Penerapan sistem telah diuji penerimaan dari pengguna, dengan mendapatkan nilai Alpha Cronbach sebesar 0.654 yang mana tingkat reabilitasnya termasuk dalam reliabel.

\section{Metodologi Penelitian}

Metode penelitian ini menggunakan Konstruktivis yang menghasilkan sebuah konstruk atau sistem yang merupakan bentuk kualitatif namun juga terdapat pengujian implementasi untuk mengukur keefektifan dari konstruk atau sistem yang dibuat [10].

\subsection{Teknik Pengumpulan data}

a. Interview

Dilakukan dengan wawancara bebas mengetahui berbagai permasalahan dalam keanggotaan PMII, sulitnya pengelolaan dan pencarian data anggota, perlunya sistem daring untuk pengisian formulir anggota juga pelaksanaan tes tertulis, dan belum adanya pengelolaan anggota terutama profil dan keaktifan anggota tersebut.

b. Observasi

Dilakukan dengan jangka waktu 15 hari mengetahui bagaimana alur dari proses pendaftaran hingga pendataan keaktifan dari anggota PMII kab. Banjar. Pada tahapan ini dikumpulkan data-data terkait variabel-variabel yang dibutuhkan untuk pendaftaran anggota hingga data-data yang diperlukan dalam keanggotaan PMII, sehingga output yang dihasilkan nantinya sesuai dengan yang dibutuhkan [11]. Beberapa data yang didapatkan yaitu rekap data anggota angkatan 2019 berjumlah 232 orang, dengan sampel data sebagai berikut:

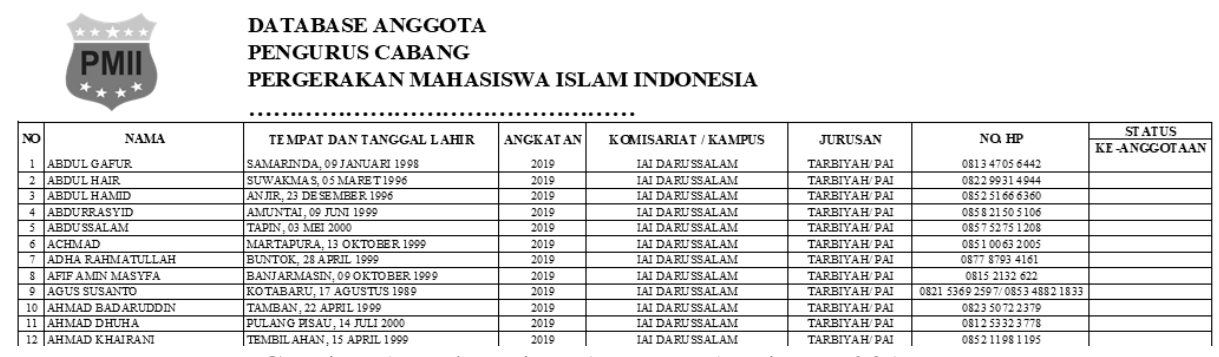

Gambar 1. Rekap data Anggota Angkatan 2019

Kekurangan data tersebut berupa ketidaklengkapan data terutama yaitu adalah tidak adanya nomor anggota dan alamat dari anggota tersebut. Sistem yang dibangun akan membuat penomoran anggota secara otomatis juga menambahkan inputan alamat dan inputan lainnya yang diperlukan sebagai data keanggotaan.

\subsection{Rancangan Sistem}

Tahapan selanjutnya dibuat rancangan-rancangan dimulai dari desain basis data, kemudian desain struktur menu dan desain antarmuka [12]. Pembuatan aplikasi dimulai dengan melihat rancangan yang telah dibuat dan disesuaikan fitur-fitur atau fungsi-fungsi yang ingin dihasilkan sesuai penemuan masalah pada penelitian ini.

Sistem nantinya memiliki beberapa tingkatan pengguna, yaitu calon peserta, peserta dan admin. Masing-masing pengguna memiliki proses yang berbeda beda. Adapun alur sistem yang dibuat mengacu pada prosedur yang telah berjalan selama ini, dengan mengubah media yang sebelumnya tatap muka dan berkumpul menjadi kegiatan daring. Alur dari Sistem Informasi Kaderisasi adalah sebagai berikut: 


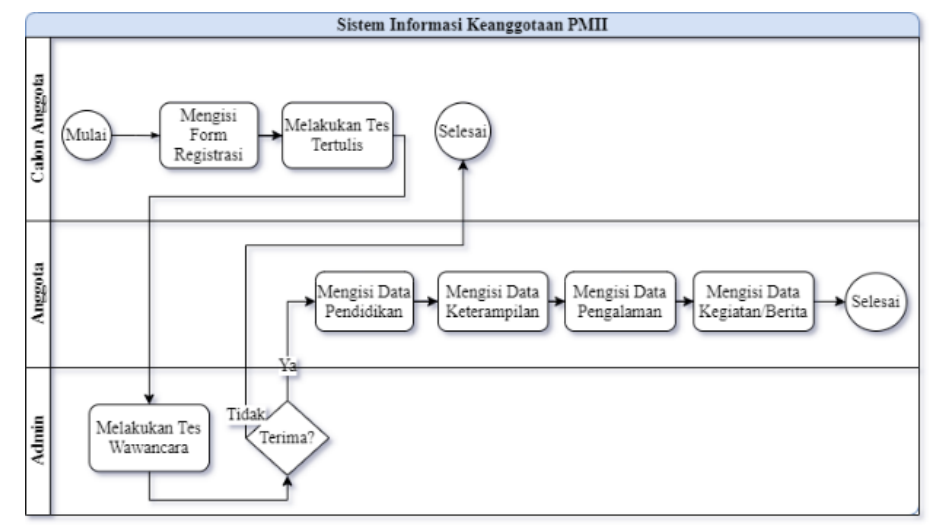

Gambar 2. Alur Sistem Informasi Kaderisasi

\subsection{Pembangunan Aplikasi}

Kemudian dilakukan pembangunan aplikasi dengan menerapkan bahasa pemrograman sehingga menjadikan adanya sistem informasi berbasis web yang mampu diberikan inputan data, memproses data hingga memberikan pelayanan pendaftaran anggota, serta menghasilkan output berupa data-data keanggotaan.

Proses pembangunan dimulai dari pembuatan database menyesuaikan dengan alur yang telah dibuat serta output yang diharapkan oleh sistem informasi nantinya. Database yang digunakan yaitu SQL Server yang mampu memberikan bahasa dan antarmuka (interface) yang baik untuk pemrograman dan komunikasi pada server [12].

Selanjutnya pembuatan web dinamis dengan web server Apache dan Hypertext Processor (PHP). Apache berfungsi sebagai tempat pengontrol dan media eksekutor dari kode PHP, sedangkan PHP merupakan bahasa pemrograman web yang bersifat open source dan berbasis teks [13]. Sedangkan bagian antarmuka menggunakan bahasa Hypertext Markup Language (HTML) agar lebih baik dalam mendapatkan rangking dari Search Engine Result Page (SERP) Google [15].

\subsection{Pengujian dan Implementasi}

Aplikasi yang telah dibangun akan melewati proses pengujian agar pada penerapannya nanti tidak terjadi kesalahan-kesalahan yang disebabkan oleh sistem. Pengujian dicoba dengan melakukan penginputan sampel data. Setelah seluruh rangkaian kegiatan diselesaikan maka aplikasi akan diimplementasikan pada tempat penelitian untuk dapat dimanfaatkan sebagaimana mestinya.

\subsection{User Acceptance}

Untuk mengetahui penerimaan pengguna dan keefektifan sistem, diperlukan pengujian terhadap pengguna. Pengumpulan data dengan model kuesioner pengujian dilakukan dalam dimulai dari analisis Validitas untuk menunjukkan tingkat kevalidan atau kesahihan suatu instrumen, kemudian analisis Realibilitas untuk memastikan pengujian tersebut memberikan hasil yang tetap [14].

\section{Hasil dan Pembahasan}

\subsection{Hasil Implementasi}

\section{a. Menu Beranda}

Pada halaman ini menampilkan halaman utama dengan logo PMII Kabupaten Banjar, dengan menu-menu yang tersedia berupa Gabung untuk bergabung ke dalam sistem dan terdapat menu login untuk mengakses sistem informasi. 


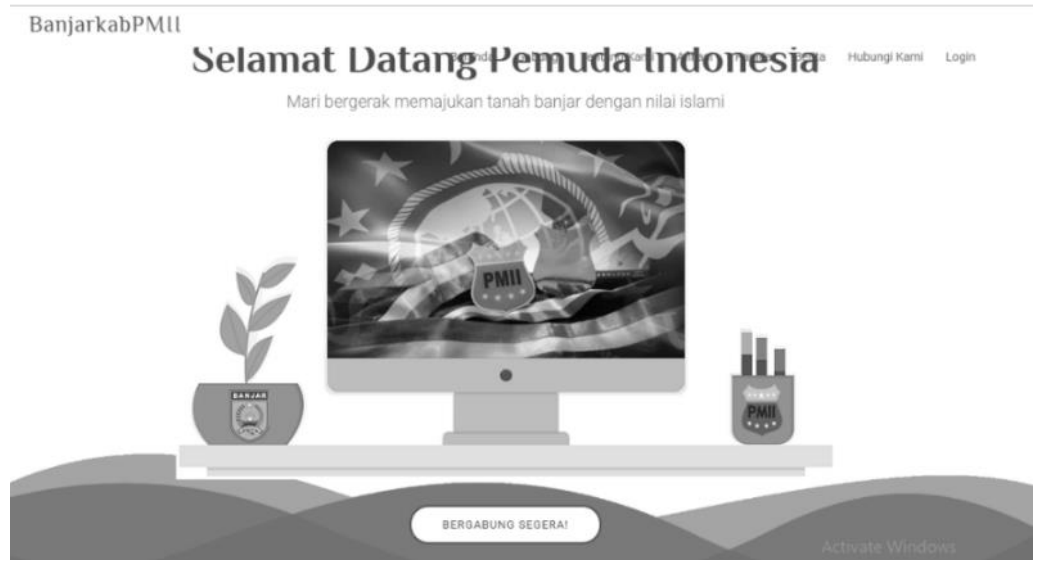

Gambar 3. Menu Beranda

b. Menu Gabung dan Masuk

Menu ini merupakan tampilan awal dari halaman gabung pendaftaran akun. Pada menu ini terdapat inputan email, password, captcha dan tombol registrasi. Kemudian menu login untuk masuk kedalam sistem informasi sebagai user tersebut.
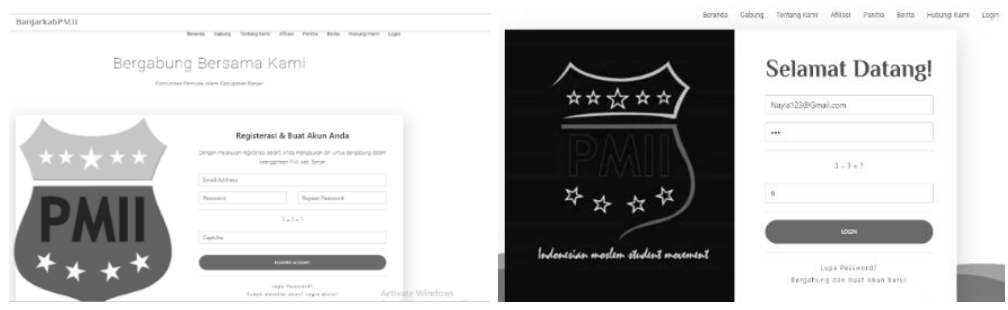

Gambar 4. Menu Gabung dan Masuk Sistem

c. Formulir Permohonan Anggota

Menu ini berfungsi untuk mengisi formulir permohonan anggota dengan data lengkap seperti nama beserta foto, alamat, tempat tanggal lahir, asal kampus dan lain-lain. Pada bagian bawah halaman terdapat tombol simpan, edit dan batal, setelah melakukan pengisian, peserta barulah dapat mengikuti proses permohonan anggota selanjutnya yaitu tes tertulis.

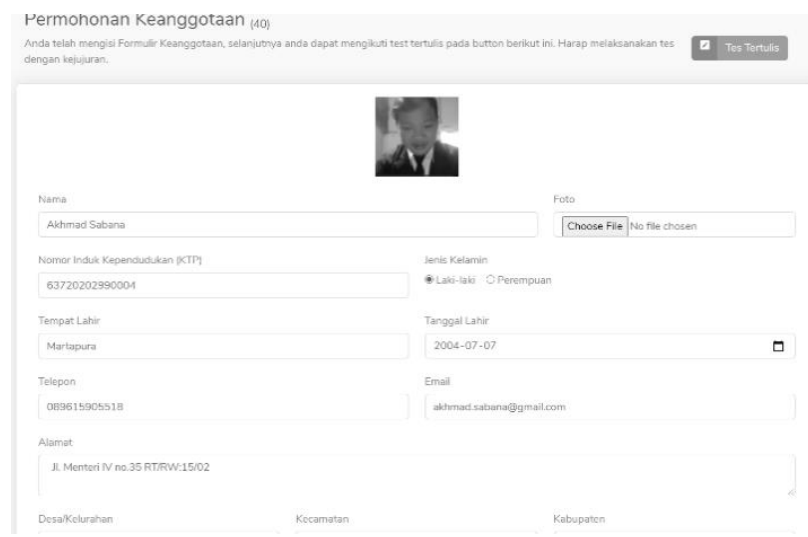

Gambar 5. Menu Permohonan Anggota

d. Tes Tertulis

Pada menu ini pemohon keanggotaan akan di berikan sebuah ujian yang berisikan beberapa pertanyaan tentang pengetahuan dasar PMII, soal-soal diinput melalu halaman admin. Apabila selesai 
mengerjakan akan ada tombol simpan pada halaman bawah menu. Setelah proses ini, pemohon tinggal menunggu tes wawancara yang dilakukan terpisah dari sistem, yaitu dengan panggilan video melalu daring ataupun sosial media.

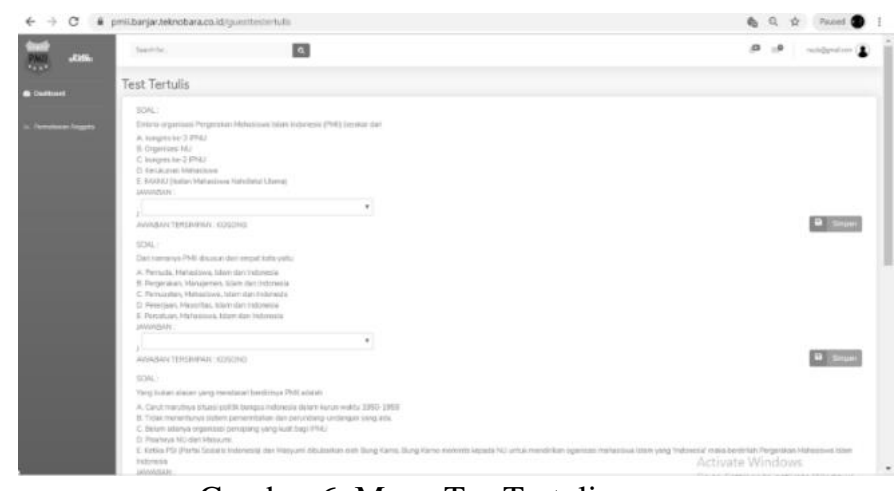

Gambar 6. Menu Tes Tertulis

e. Isi Nilai Wawancara

Menu ini dapat diakses oleh admin yang mana berfungsi untuk menginputkan penilaian hasil dari wawancara yang dilakukan oleh admin dengan menilai beberapa aspek yang telah ada. Aspekaspek dapat ditambahkan atau dirubah pada login admin.

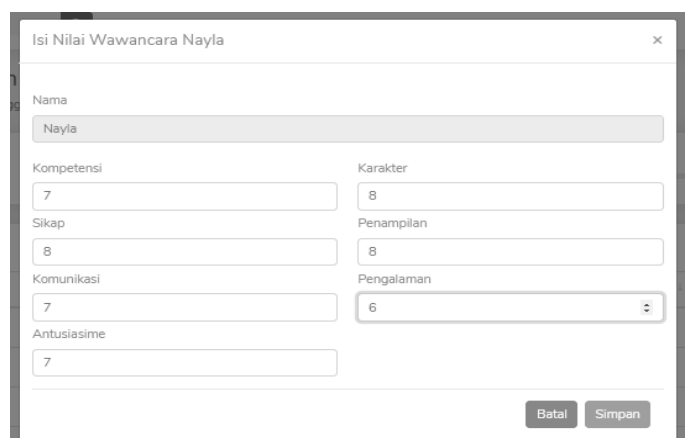

Gambar 7. Menu Isi Nilai Wawancara

\section{f. Profil Anggota}

Pada menu ini berfungsi melihat isi profil lengkap anggota PMII yang telah terdaftar pada PMII Kab.Banjar. Mulai dari data profil hasil dari formulir pendaftaran, nilai dari hasil tes tertulis dan wawancara juga inputan anggota meliputi pendidikan, keterampilan, pengalaman dan kegiatan yang telah diinput oleh anggota tersebut dan telah dimoderasi / validasi oleh admin.
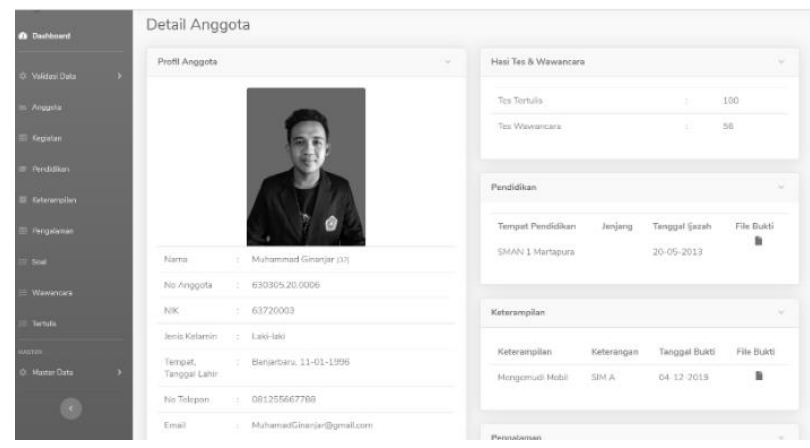

Gambar 8. Menu Profil Anggota 


\subsection{Penerimaan Pemakai}

Pengujian User Acceptance dilakukan pada penelitian ini agar mengetahui bahwa aplikasi yang telah dibuat ini layak atau masih memiliki banyak kekurangan. Pengujian User Acceptance ini menggunakan kuisioner yang diberikan kepada 15 responden berdasarkan model skala likert (lima pilihan jawaban) yaitu : Skor $1=$ Sangat Tidak Setuju (STS), Skor $2=$ Tidak Setuju (TS), Skor 3 = Cukup Setuju (CS), Skor 4 = Setuju (S), Skor 5 = Sangat Setuju (SS). Berikut adalah kuisioner yang diberikan dan hasil yang didapatkan dari seluruh responden seperti tabel berikut :

Tabel 1. Pertanyaan Kuisoner

\begin{tabular}{|c|c|c|c|c|c|c|}
\hline \multirow[t]{2}{*}{ No } & \multirow[t]{2}{*}{ Pertanyaan } & \multicolumn{5}{|c|}{ Jawaban } \\
\hline & & STS & TS & CS & $\mathbf{S}$ & SS \\
\hline 1 & Apakah aplikasi ini mudah dioperasiakan atau digunakan? & & & & & \\
\hline 2 & $\begin{array}{l}\text { Apakah aplikasi ini menu-menu dan tombol-tombolnya } \\
\text { sudah cukup lengkap? }\end{array}$ & & & & & \\
\hline 3 & $\begin{array}{l}\text { Apakah aplikasi ini sudah dapat melakukan } \\
\text { Pendaftaran secara online pada PMII Kab.Banjar? }\end{array}$ & & & & & \\
\hline 4 & $\begin{array}{l}\text { Apakah aplikasi ini dapat membantu anda dalam } \\
\text { melakukan Pendaftaran secara online pada PMII } \\
\text { Kab.Banjar? }\end{array}$ & & & & & \\
\hline 5 & $\begin{array}{l}\text { Apakah aplikasi ini sudah dapat memberikan informasi atau } \\
\text { laporan tentang keanggotaan anda dalam PMII Kab.Banjar? }\end{array}$ & & & & & \\
\hline
\end{tabular}

Tabel 2. Pertanyaan Kuisoner

\begin{tabular}{|l|l|l|l|l|l|l|l|}
\hline Tanggapan & $\begin{array}{c}\text { Pertanyaan } \\
\mathbf{1}\end{array}$ & $\begin{array}{c}\text { Pertanyaan } \\
\mathbf{2}\end{array}$ & $\begin{array}{c}\text { Pertanyaan } \\
\mathbf{3}\end{array}$ & $\begin{array}{c}\text { Pertanyaan } \\
\mathbf{4}\end{array}$ & $\begin{array}{c}\text { Pertanyaan } \\
\mathbf{5}\end{array}$ & $\begin{array}{c}\text { Jumlah } \\
\text { presentase } \\
(\%)\end{array}$ & $\begin{array}{c}\text { Rata- } \\
\text { Rata } \\
\text { Presenta } \\
\text { se }(\boldsymbol{\%})\end{array}$ \\
\hline $\begin{array}{l}\text { Sangat } \\
\text { Setuju }\end{array}$ & $77.46 \%$ & $89.04 \%$ & $89.04 \%$ & $77.46 \%$ & $65.22 \%$ & $398.22 \%$ & $79.64 \%$ \\
\hline Setuju & $22.54 \%$ & $10.96 \%$ & $10.96 \%$ & $22.54 \%$ & $34.78 \%$ & $101.78 \%$ & $20.36 \%$ \\
\hline $\begin{array}{l}\text { Cukup } \\
\text { Setuju }\end{array}$ & $0.00 \%$ & $0.00 \%$ & $0.00 \%$ & $0.00 \%$ & $0.00 \%$ & $0.00 \%$ & $0.00 \%$ \\
\hline $\begin{array}{l}\text { Todak } \\
\text { Setuju }\end{array}$ & $0.00 \%$ & $0.00 \%$ & $0.00 \%$ & $0.00 \%$ & $0.00 \%$ & $0.00 \%$ & $0.00 \%$ \\
\hline $\begin{array}{l}\text { Sangat } \\
\text { Tidak } \\
\text { Setuju }\end{array}$ & $0.00 \%$ & $0.00 \%$ & $0.00 \%$ & $0.00 \%$ & $0.00 \%$ & $0.00 \%$ & $0.00 \%$ \\
\hline Total & $\mathbf{1 0 0 \%}$ & $\mathbf{1 0 0 \%}$ & $\mathbf{1 0 0 \%}$ & $\mathbf{1 0 0 \%}$ & $\mathbf{1 0 0 \%}$ & $\mathbf{5 0 0 \%}$ & $\mathbf{1 0 0 \%}$ \\
\hline
\end{tabular}

Berdasarkan tabel diatas yang didapatkan dari pengujian kuisioner, maka dapat disimpulkan bahwa aplikasi yang dibangun sudah sesuai dengan tujuan yaitu dapat membantu dalam pendaftaran anggota baru pada PMII Kab Banjar.

Setelah didapat hasil kuisionernya, maka selanjutnya adalah divalidasi dengan korelasi orang dilanjutkan uji reabilitas [15]. Berikut hasil Perhitungan Korelasi dan Uji Reabilitas: 
Tabel 3. Hasil Perhitungan Korelasi Person

\begin{tabular}{|c|c|c|c|c|c|c|c|}
\hline \multirow[t]{2}{*}{ No } & \multirow[t]{2}{*}{ Responden } & \multicolumn{5}{|c|}{ Pertanyaan ke- } & \multirow[t]{2}{*}{ Jumlah } \\
\hline & & 1 & 2 & 3 & 4 & 5 & \\
\hline 1 & Responden 1 & 4 & 5 & 5 & 4 & 4 & 21 \\
\hline 2 & Responden 2 & 4 & 5 & 5 & 5 & 5 & 24 \\
\hline 3 & Responden 3 & 4 & 5 & 5 & 4 & 4 & 22 \\
\hline 4 & Responden 4 & 5 & 4 & 5 & 5 & 4 & 23 \\
\hline 5 & Responden 5 & 4 & 4 & 5 & 4 & 4 & 21 \\
\hline 6 & Responden 6 & 5 & 5 & 4 & 5 & 4 & 23 \\
\hline 7 & Responden 7 & 5 & 5 & 5 & 5 & 5 & 25 \\
\hline 8 & Responden 8 & 5 & 5 & 5 & 5 & 5 & 25 \\
\hline 9 & Responden 9 & 5 & 5 & 5 & 5 & 5 & 25 \\
\hline 10 & Responden 10 & 5 & 5 & 5 & 5 & 5 & 25 \\
\hline 11 & Responden 11 & 5 & 5 & 5 & 5 & 5 & 25 \\
\hline 12 & Responden 12 & 5 & 5 & 5 & 5 & 5 & 25 \\
\hline 13 & Responden 13 & 5 & 5 & 4 & 4 & 4 & 22 \\
\hline 14 & Responden 14 & 5 & 5 & 5 & 5 & 5 & 25 \\
\hline 15 & Responden 15 & 5 & 5 & 5 & 5 & 5 & 25 \\
\hline & $r_{x y}$ & 0.685 & 0.446 & 0.568 & 0.882 & 0.927 & \\
\hline & $t_{\text {hitung }}$ & 3.389 & 1.794 & 2.488 & 6.765 & 8.938 & \\
\hline & $t_{\text {tabel }}(95 \%, 13)$ & 1.771 & & & & & \\
\hline & Keterangan & valid & Valid & valid & valid & valid & \\
\hline & Jumlah Valid & 5 & & & & & \\
\hline
\end{tabular}

Tabel 4. Hasil Uji Reliabilitas

\begin{tabular}{|c|c|c|c|c|c|c|c|}
\hline \multirow[t]{2}{*}{ No } & \multirow[t]{2}{*}{ Responden } & \multicolumn{5}{|c|}{ Pertanyaan ke- } & \multirow[t]{2}{*}{ Jumlah } \\
\hline & & 1 & 2 & 3 & 4 & 5 & \\
\hline 1 & Responden 1 & 4 & 5 & 5 & 4 & 4 & 21 \\
\hline 2 & Responden 2 & 4 & 5 & 5 & 5 & 5 & 24 \\
\hline 3 & Responden 3 & 4 & 5 & 5 & 4 & 4 & 22 \\
\hline 4 & Responden 4 & 5 & 4 & 5 & 5 & 4 & 23 \\
\hline 5 & Responden 5 & 4 & 4 & 5 & 4 & 4 & 21 \\
\hline 6 & Responden 6 & 5 & 5 & 4 & 5 & 4 & 23 \\
\hline 7 & Responden 7 & 5 & 5 & 5 & 5 & 5 & 25 \\
\hline 8 & Responden 8 & 5 & 5 & 5 & 5 & 5 & 25 \\
\hline 9 & Responden 9 & 5 & 5 & 5 & 5 & 5 & 25 \\
\hline 10 & Responden 10 & 5 & 5 & 5 & 5 & 5 & 25 \\
\hline
\end{tabular}




\begin{tabular}{|l|l|c|c|c|c|c|c|}
\hline $\mathbf{1 1}$ & Responden 11 & 5 & 5 & 5 & 5 & 5 & 25 \\
\hline $\mathbf{1 2}$ & Responden 12 & 5 & 5 & 5 & 5 & 5 & 25 \\
\hline $\mathbf{1 3}$ & Responden 13 & 5 & 5 & 4 & 4 & 4 & 22 \\
\hline $\mathbf{1 4}$ & Responden 14 & 5 & 5 & 5 & 5 & 5 & 25 \\
\hline VAR ITEM & Responden 15 & 5 & 5 & 5 & 5 & 5 & 25 \\
\hline SVAR ITEM & 0.210 & 0.124 & 0.171 & 0.210 & 0.257 & \\
\hline \multicolumn{2}{|l|}{ SVAR TOTAL } & 0.971 & & & & & \\
\hline
\end{tabular}

Dari Tabel 4, didapat nilai Alpha Cronbach adalah 0,654 dengan jumlah pertanyaan 5 buah. Alpha Cronbach $=0,654$ terletak antara 0,60 hingga 0,80 sehingga tingkat reliabilitasnya reliable. Dari semua hasil pengujian yang telah dilakukan dari pengujian validitas maupun reliabilitas menunjukkan bahwa pengujian User Acceptance ini telah menghasilkan data yang valid dengan tingkat reabilitasnya termasuk Reliabel.

\section{Kesimpulan}

Kesimpulan yang didapatkan dari permasalahan yang ditemukan hingga terselesaikannnya dengan adanya Sistem Informasi Kaderisasi PMII Kabupaten Banjar, yaitu:

a. Dengan dibangunnya Sistem Informasi Kaderisasi, data anggota dapat dengan mudah untuk ditemukan dan dicari dikarenakan telah tersimpan kedalam database dan adanya pengelolaan memudahkan pencarian anggota.

b. Sistem Informasi Kaderisasi yang dibuat mampu menjadi layanan daring untuk pendaftaran anggota dimulai dari pengisian formulir, tes tertulis dan penginputan nilai wawancara.

c. Pada Sistem Informasi ini tes tertulis, wawancara memiliki nilai yang tersimpan pada database, kemudian setiap inputan pendidikan, keterampilan, pengalaman dan kegiatan dari anggota dapat diberikan nilai yang mana penilaian-penilaian dapat dijadikan acuan untuk penilaian keanggotaan PMII maupun untuk pemilihan kepanitiaan PMII.

d. Sistem informasi yang dibuat telah melakukan pengujian dan dapat diterima dengan baik oleh pengguna dengan tingkat reabilitas sebesar 0,654 .

\section{Daftar Pustaka}

[1] Indrajit and R. Eko, Manajemen sistem informasi dan teknologi informasi., Jakarta: PT Elex Media Komputindo, 2000.

[2] S. Jumaili, "Kepercayaan terhadap teknologi sistem informasi baru dalam evaluasi kinerja individual," in Simposium Nasional Akuntansi VIII, Solo, 2005.

[3] Junaidi, "Manajemen pengkaderan organisasi kepemudaan: Studi terhadap strategi kaderisasi PMII Cabang Kota Semarang tahun 2010-2012 dalam meningkatkan aktifitas mahasiswa," IAIN Walisongo, Semarang, 2014.

[4] M. A. G. Muhlas Adi Putra, "Pola Komunikasi Organisasi Pergerakan Mahasiswa Islam (PMII) di kota Malang," JISIP: Jurnal Ilmu Sosial dan Ilmu Politik, p. 1, 2018. 
[5] H. A. K. D. Mohammad Amin, "Peran Kaderisasi Formal Dalam Meningkatkan Kualitas SDM Dalam Organisasi Kemahasiwaan ( Studi Kasus Pada PMII Cabang Kota Malang )," EJRM : e - Jurnal Riset Manajemen, p. 1, 2019.

[6] M. Zainuddin, Nalar Pergerakan Anggota PMII, Yogyakarta: Naila Pustaka, 2015.

[7] A. Hifni, Menjadi Kader PMII, Yogyakarta: Moderate Muslim Society (MMS), 2016.

[8] Y. D. M. D. Khodijah Hulliyaha, "Sistem Informasi Keanggotaan Kesatuan Aksi Mahasiswa Muslim Indonesia (KAMMI) Daerah Jakarta," UIN Syarif Hidayatullah Jakarta Sain Tek, p. 1, 2016.

[9] I. T. Islamy, H. M. Astuti and R. P. Wibowo, "Perancangan dan Pembuatan Sistem Pelaporan Kinerja Berbasis Online untuk Pranata Komputer," JUITA: Jurnal Informatika, vol. 8, no. 1, pp. 91-100, 2020.

[10] F. Wahid, "Metodologi penelitian sistem informasi: sebuah gambaran umum," Media Informatika, vol. 2, no. 1, pp. 69-81, 2004.

[11] Y. Sari and I. Prasetia, "Sistem Informasi Manajemen Berbasis UML (Studi Kasus Pemeliharaan Toilet pada Kampus Fakultas Teknik Universitas Lambung Mangkurat)," Jurnal Teknologi Informasi Universitas Lambung Mangkurat (JTIULM), pp. 59-65, 2016.

[12] Zuriati, "The Design of the Information System of New Student Admission," ESAI, vol. 6, no. 3, pp. 155165, 2012.

[13] M. Alkaff, "Rancang Bangun Sistem Informasi Penjualan Meubel (Studi Kasus: CV. Fajar Indah Amuntai)," Jurnal Teknologi Informasi Universitas Lambung Mangkurat (JTIULM), pp. 9-17, 2016.

[14] D. P. Oktavian, Menjadi Programmer Jempolan dengan PHP, Yogyakarta: Mediakom, 2010.

[15] Y. A. Andika Saputra, "Analisis Pengaruh Struktur HTML Terhadap Rangking Search Engine Result Page," Jurnal Mantik Penusa, vol. 2, no. 2, pp. 34-39, 2019. 